\title{
Sex differences in traumatic brain injury: a multi-dimensional exploration in genes, hormones, cells, individuals, and society
}

\author{
Cheng $\mathrm{Ma}^{1+}$, Xin $\mathrm{Wu}^{1+}$, Xiaotian Shen ${ }^{2}$, Yanbo Yang ${ }^{1}$, Zhouqing Chen ${ }^{1}$, Xiaoou Sun ${ }^{1}$ and Zhong Wang ${ }^{{ }^{*}}$
}

\begin{abstract}
Traumatic brain injury (TBI) is exceptionally prevalent in society and often imposes a massive burden on patients' families and poor prognosis. The evidence reviewed here suggests that gender can influence clinical outcomes of TBI in many aspects, ranges from patients' mortality and short-term outcome to their long-term outcome, as well as the incidence of cognitive impairment. We mainly focused on the causes and mechanisms underlying the differences between male and female after TBI, from both biological and sociological views. As it turns out that multiple factors contribute to the gender differences after TBI, not merely the perspective of gender and sex hormones. Centered on this, we discussed how female steroid hormones exert neuroprotective effects through the anti-inflammatory and antioxidant mechanism, along with the cognitive impairment and the social integration problems it caused. As to the treatment, both instant and long-term treatment of TBI requires adjustments according to gender. A further study with more focus on this topic is therefore suggested to provide better treatment options for these patients.
\end{abstract}

Keywords: Traumatic brain injury, Gender, Sex differences, Female steroids, Microglia, Cognitive impairment, Dopamine, Social impairment

\section{Main text}

When an external force suddenly acts on the brain, the brain is severely traumatized in a moment, causing a series of physiological and psychological damage. Previous survey shows that there are 150-315 people suffering from traumatic brain injury (TBI) in every 100,000 people [1], and this ratio is still increasing with the development of transportation, especially in developing countries [2]. In 2014, TBI accounted for nearly 2.87 million emergency visits, 288,000 hospitalizations, and more than 56,800 deaths in the USA [3]. Thus, TBI has becoming a social and economic burden and poses a challenge to public health simultaneously because of the high incidence, mortality, and disability rate, as well as the grand expense of rehabilitation.

\footnotetext{
* Correspondence: wangzhong761@163.com

${ }^{+}$Cheng Ma and Xin Wu contributed equally to this work.

${ }^{1}$ Department of Neurosurgery \& Brain and Nerve Research Laboratory, The First Affiliated Hospital of Soochow University, Jiangsu Province, 188 Shizi Street, Suzhou 215006, China

Full list of author information is available at the end of the article
}

Multiple researches have revealed sex differences in TBI. They noted that the number of male patients is higher than female [4-6], due to the increased probability of injury in males. What is more, men and women are different in growing environment, neurodevelopment, and sociological attributes [7], which is hard to neglect and may also contribute to the difference [8-10].

Gender-related physiological differences have been confirmed in animal experiments, and the results of clinical trials of TBI and gender differences are still unclear. Most of them focus on the different hormone levels caused different reproductive structures. When TBI happens, estrogen and progesterone can play various neuroprotective functions such as reduce intracranial pressure (ICP), improve cerebral perfusion pressure (CPP), and neurological score [11]. However, the neuroprotective mechanisms of estrogen and progesterone are still controversial and need further research. Also, researchers begin to focus on the role of microglia, which previously focused on male subjects, but started to shift to the other gender recently.

(C) The Author(s). 2019 Open Access This article is distributed under the terms of the Creative Commons Attribution 4.0 International License (http://creativecommons.org/licenses/by/4.0/), which permits unrestricted use, distribution, and reproduction in any medium, provided you give appropriate credit to the original author(s) and the source, provide a link to the Creative Commons license, and indicate if changes were made. The Creative Commons Public Domain Dedication waiver (http://creativecommons.org/publicdomain/zero/1.0/) applies to the data made available in this article, unless otherwise stated. 
Here, we briefly outlined what is currently known about gender differences in TBI at clinical and pre-clinical levels to serve further research (Fig. 1). We concluded that a variety of factors regulates sex differences in TBI, and it is believed that differences in cognitive impairment after TBI can guide further clinical treatment.

\section{The fundamental difference}

The fundamental difference between male and female originates from the sex chromosome, gender is male or female is determined by the $\mathrm{Y}$ chromosome gene, sex chromosomes determine the difference in structure between men and women [12, 13]. Through a series of complicated processes, human beings are physically divided into men and women. When it comes to the brain, there are no apparent structural differences between males and females. However, previous studies have demonstrated minor differences on weight, fine structure, and functional anatomy on human brain across different sexes [14-18]. Since the brain indeed has a "gender," it is necessary to study and analyze it.

\section{Sex differences in outcomes after TBI}

TBI is a complex process, except for the trauma itself, which brings a series of follow-up problems that lead to the diversity of the outcome. Among the many factors that may influence the prognosis, gender is one of the most controversial. Several studies proved that women have a worse clinical outcome than men after TBI [19-23]. Clinical research including 1627 TBI patients which categorized them into the pediatric group ( $<19$ years), middle group (19-60 years), and elderly group ( $>60$ years) by their age found that female TBI group differs in the severity of injury and mortality from male significantly [24]. The mortality rates for male and female were $1.6 \%$ and $3.4 \%$, respectively. They also found that the degree of damage measured by the Glasgow Coma Scale (GCS) shows that female performed worse. Besides, female aged

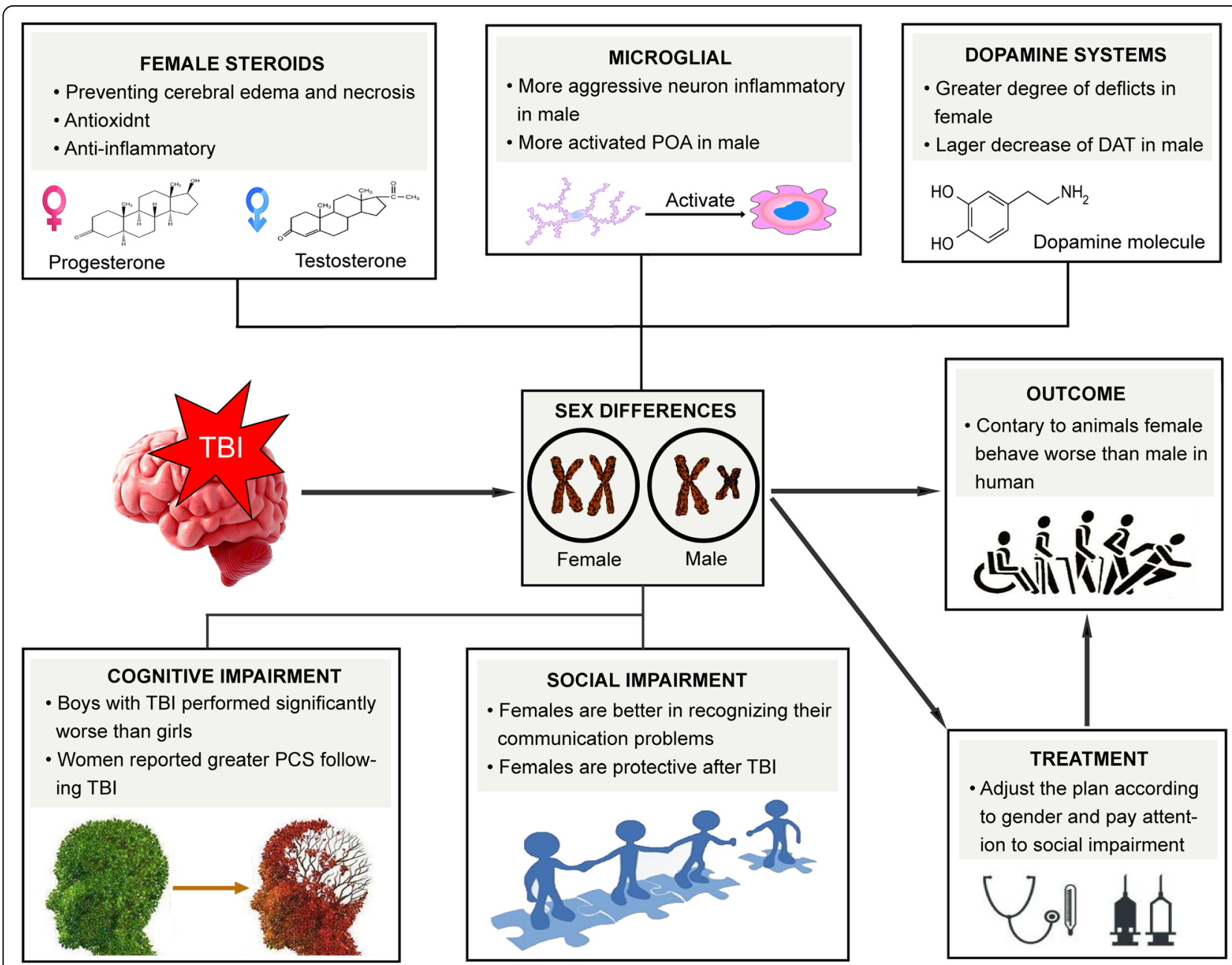

Fig. 1 Sex difference after TBI is composed of many factors such as steroids, microglial, and dopamine system. These factors work together and contribute to the outcome 
30 years or older had a poorer outcome than either males or females younger than 30 measured by the Glasgow Outcome Scale (GOS) [22].

On the other hand, women tend to have fewer complications after TBI [25], and they usually perform better in prognoses and outcomes [26-30]. Premenopausal women have a better prognosis due increased level of sex hormones [19]. In contrast to the prepubescent female, the pubescent female has lower mortality after isolated moderate-to-severe TBI [31]. In older adults, a study indicated that no sex differences were found in mortality following isolated TBI [32]. An investigator observed 427 TBI patients found no gender difference on Glasgow Outcome Scale while age and initial injury severity had an effect on the GOS [33].

The conclusions of these studies are reversed [32, 34], as TBI outcome is affected by many confounding factors, such as age, severity of TBI, and physical condition of the patient [35-38]. Males are usually disproportionately represented in many studies [31, 39]. The subjects included in the experiment are often males, and the gender differences between male and female are neglected. Therefore, it is necessary to study the gender differences of TBI.

\section{The effect of female steroids after TBI}

As mentioned above, the difference in endogenous hormones may contribute to sex differences after TBI [40]. Steroids such as progesterone and their metabolites protect glial cells and neurons by preventing the brain from edema, necrosis, apoptosis, and inflammation [41-44]. Animal experiments have proven that estrogen and progesterone both play a crucial role in gender differences after TBI $[45,46]$.

Recent evidence also suggests that estrogen and progesterone levels act as a critical factor in the prognosis of traumatic brain injury. It has been confirmed that the decrease in $17 \beta$-estradiol (E2) level leads to an increase in brain damage, while in the proestrus period when the E2 level is high, brain damage is lower [47]. E2 also acts as a neuroprotective factor against stroke in ovariectomized (OVX) animal models [48], which reveals that serum estrogen and progesterone may decrease post-traumatic brain water volume. When applied with pharmacological dose of estrogen and progesterone, male and OVX female rats with TBI model shows a decreased intracranial pressure, improved cerebral perfusion, and increased neurological function score [11].

Several studies have investigated the possible mechanism of the protective effect of estrogen and progesterone [49]. Thirty minutes after a moderate TBI, hormones or vehicle were intraperitoneally injected, and the levels of proinflammatory cytokines in the brain were measured at 6 and $24 \mathrm{~h}$. The events in the central nervous system after TBI occur in acute and chronic recovery phases, and the former includes a primary and secondary step [50]. At the primary and secondary stage, proinflammatory cytokines such as interleukin-6 (IL-6), interleukin-1 beta (IL-1ß), transforming growth factor-beta (TGF- $\beta$ ), and tumor necrosis factoralpha (TNF- $\alpha$ ) are influenced by progesterone and estrogen. Cytokines like IL-1 $\beta$, IL-6, and TNF- $\alpha$ are confirmed to promote inflammatory responses [51], and increased levels of these proinflammatory cytokines have been observed in the cerebrospinal fluid of brain parenchyma tissues and can intensify the brain lesions that occur during trauma $[52,53]$. Thus, the neuroprotective effects of progesterone may be partially caused by a decreased level of anti-inflammatory cytokines including TNF- $\alpha$ at the primary step as well as IL-6 either at the primary or second step after TBI. The neuroprotective effect of estrogen may be partially caused by decreased IL-1 $\beta$ level in the second stage. Besides, higher TNF- $\alpha$ is beneficial in the second step since it can promote the production of the nerve growth factor [54]; thus, estrogen acts as a protective effect in the secondary phase mediated by improving levels of TNF- $\alpha$ (Fig. 2). TGF- $\beta$ exerts anti-inflammatory effects by inhibiting the levels of IL-1 $\beta$, TNF- $\alpha$, and oxygen-free radicals. The antiinflammatory effect of TGF is higher than that of inflammatory effects. Increased TGF- $\beta$ is part of the mechanism of anti-inflammatory [55].

Hormone-regulated antioxidant mechanisms are also responsible for gender differences after TBI [19]. The secondary damage after TBI is mainly caused by hypoperfusion of the brain, lipid peroxidation along with the free radical production induced by ischemia [56]. Progesterone treatment in male rats after frontal cortex contusion leads to lower lipid peroxidation [57]. A similar research investigated the level of F2-isoprostane, which is widely used as biomarkers of lipid peroxidation [58]; in 68 TBI patients, they found that male has a higher level of F2-isoprostane than females in CSF [53]. These studies indicate that the neuroprotective effect of progesterone may contribute to its anti-lipid peroxidation function. When it comes to estrogen, it has been shown to have even better antioxidation effects than the most widely used antioxidant supplement vitamin $\mathrm{E}$ [59]. Protein carbonylation is used as a marker of the level of oxidative stress in the nervous system because it is a product of the oxidative period $[60,61]$. Both female and male rats have a distinct increase in carbonylation after TBI in the injured area. However, when it comes to the field far away from the wounded zone, such as the ependymal tissue of the third ventricle and median eminence, the male has higher carbonylation expression. Considering progesterone also regulates metabolic functions in the nerve system [62] and acts the anti-excitotoxicity effect of TBI, progesterone may play a decisive role in reducing protein carbonization in the female, and the detailed mechanism still needs further research. 


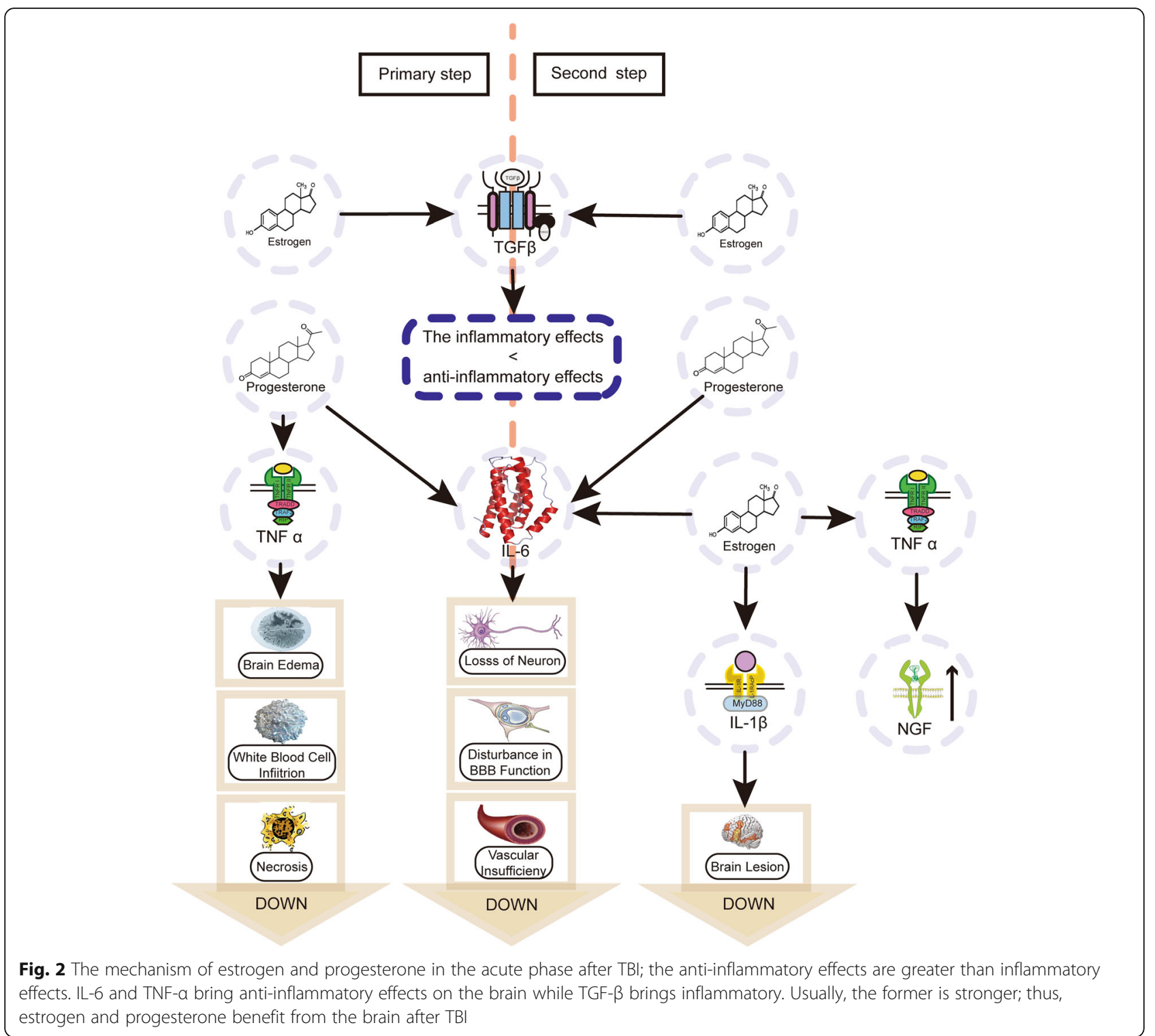

\section{Sex differences in microglia after TBI}

Microglia are resident macrophages in the brain and play a key role in brain sexual development via secretion of cytokines and growth factors [63-67]. Although microglia had infiltrated to the brain and started to colonize before there was a distinct gender difference [68], its sexual dimorphism during the development of growth has been detected [69]. In the early postnatal period, microglia are in a primarily activated state $[70,71]$. By the end of the third postnatal week, testosterone produced by male testis aromatized into estradiol to induce brain masculinization [72].

Preoptic area (POA) of the hypothalamus is thought to be responsible for thermoregulation and male sexual behavior, and recent studies have indicated that the number and activation state of microglial cells in female rat pups are less than male rat pups in this region [73, 74].
During the brain masculinization, estradiol leads to the upregulation of PGE2, and microglia amplify this signaling pathway to induce the development of masculine dendritic spine phenotype [73]. Similar differences also exist in the hippocampus, amygdala, and parietal cortex [71]. This phenomenon proves the interaction between microglial and sex hormones. Also, it is confirmed that after TBI, the level of activated microglia in the cortex of male rats is far higher than that of female [75]. Microglia of 60-day-old female rats have a higher level of IL- 1 and less IL-10 expression compared with male rats [71], while no difference in estrogen receptors was found [76]. With Iba1 immunofluorescence staining, males present higher density near the lesion compared with females after TBI [35].

Moreover, this difference may also link to female steroid hormones on microglia as a pre-clinical study of rat 
ischemia-reperfusion model found similar levels of microglial activation between male and ovariectomized female mice treated with $17 \beta$-estradiol [73, 77]. When inhibiting the microglia, the production of PGE2 is restrained, which means that the microglia affect the production of these hormones [73]. Those hormones can show a neuroprotective function when used after neural injury by reducing the level of reactive microglia, which eventually avoid the overactivated inflammatory period [78]. The view of microglia has transferred from a kind of negative role to positive and protective debris elimination [79].

Existing studies on gender differences of microglia in TBI mainly focus on the interaction of microglia and sex hormones, and studies on other mechanisms of microglia are still insufficient.

\section{Sex differences in dopamine systems after TBI}

To our knowledge, dopamine (DA) systems can mediate multiple aspects of cognition [80], CT scan shows that dopamine transporter (DAT) reduce chronically after TBI [81]. A study involved 24 male and 24 female rats which revealed that compared to females, males have a decrease in DAT expression caused by CCI [82]. Vesicular monoamine transporter-2 (VMAT-2), which is an integral membrane protein transport monoamines, can isolate DA to prevent its oxidation in the cytoplasm and can also sequester neurotoxins in vesicles [83]. Female rats are more susceptible to the inhibition of VMAT-2 after TBI, which leads to a more severe deficit in female rats when the function of DA-storage and VMAT-2 is inhibited after TBI [84].

Estrogen may exert an influence on this process, as it has been proven to regulate DA systems through genomic and nongenomic mechanisms, but the detailed mechanism is still unknown [85]. The extracellular difference happens mainly at the part of dopamine release and synthesis [86]. Females also have a higher density of DAT binding site than males [87-89]. Thus, although the specific mechanism is unclear, there is a particular gender difference in the dopamine system after TBI. A clinical trial included 193 adults of severe TBI observed a significant relationship between sex and DA pathway, which indicates that sex-specific treatment of drugs involved in DA pathway might be a way to improve the overall cognitive recovery for TBI patients in the future [90].

\section{Sex differences in cognitive impairment after TBI}

Cognitive function impairment is a common complication after TBI, which adds a huge burden to the patient's recovery $[8,19]$. In the existing literature, when evaluating cognitive recovery in patients with TBI, men usually have a better recovery on verbal tasks while women can restore their spatial positioning at a faster speed [91-93].
Post-concussive symptoms (PCS) are a set of symptoms that comes after TBI, including loss of memory, difficulty in concentrating, and personality change [94]. Females are more frequently to be reported as patients of PCS compared to male. A meta-analysis pointed out that although men are more frequently to suffer from TBI, worse prognosis is found to be related to female sex [20]. The reason why female patients reported elevated PCS could be partially explained by a risk factor called anxiety sensitivity (AS), which is the tendency to perceive general environmental stimulus as harm or danger [59]. Women have been reported elevated AS both in nonclinical [59] and clinical samples [95]. It is confirmed that patients with higher AS tends to exaggerate PCS symptoms by amplifying its severity [96].

As to the pediatric population, gender can also be a factor that contributes to the different cognitive outcomes after TBI [97]. Boys with TBI performed significantly worse than girls with TBI on the California Verbal Learning Test, which is a neuropsychological test used to evaluate verbal learning and memory capability [98]. Another investigation revealed that boys performed worse than girls and even worse than their counterparts in the control group [99]. This difference is not feasible with sex hormones because the hormone level of male and female is roughly the same before sexual maturity.

In general, due to the complexity of cognitive function, a single clinical test cannot fully assess the difference between male and female in this aspect. Further work needs to be done to establish a throughout understanding of cognitive function changes in patients with TBI.

\section{Sex differences in social impairment after TBI}

After a moderate or severe TBI, patients usually suffer from social impairment when patients trying to return to society $[100,101]$, because social and behavioral competencies are vulnerable to compromise in brain trauma [102]. Patients may show inappropriate behaviors or loss of social functions [103]. Even children after TBI have a higher risk to be rejected by their friends and lead to long-term social and behavioral problems [104]. Identifying the different social impairment level on each gender may better guide clinical treatment and interventions.

TBI can also lead to language function impairment. Patients after TBI may have difficulty in organizing language and conceiving linguistic stimulus [105, 106]. A research investigated 160 adults with TBI and 81 adults without TBI; by using a standardized measurement of communication problems in everyday life, they found that when communication problems happen, female patients are more accessible to recognize their situations and try to solve them [82]. A late meta-analysis reported that over $39 \%$ of patients in the chronic phase after moderate or severe TBI have a significant impairment at recognizing facial affect 
[107]. The area injured and the severity of the brain may be a risk factor since different parts of the brain have different functions [108]. However, other sources reported that patients with TBI who had damaged the emotion recognition regions did not perform significantly worse than those who had damage in other brain regions [109]. Because plenty of researches have proven the female advantage in recognizing emotion [110], gender may be a potential predictor of emotion recognition deficits. A recent study which tested 53 individuals with TBI and 49 comparisons by both static and dynamic tests found that male patients performed significantly worse not only than female patients but also than comparison participants in the dynamic task [111].

These findings suggested that female gender may play a protective role for social impairment after TBI, although there are opposite results in the animal experiment. Species may cause the differences between human and mice [112] since social communication of animal is much simpler.

\section{Sex differences in treatment after TBI}

Since gender differences exist in the outcome, clinical manifestation, and cognitive impairment after TBI, we have reasons to speculate gender differences in the treatment after TBI. Studying gender differences in treatment after TBI can provide theoretical support for gender-specific treatment at the clinical stage and improve the treatment outcomes. The first idea to break into the brain is to treat with hormones.

As mentioned before, female steroids affect patients through a series of mechanisms. Hormones have begun to be used in the treatment of nervous system damage [113], but it still needs to be adjusted according to gender. Administration of estrogen can increase dendritic spines and improves synaptic connectivity [114, 115]. Tests for post-injury motor function have shown that men have better neurological recovery through estrogen therapy [116]. When male and female are treated with estrogen, female tends to show more adverse effects because the receptors of estrogen of the female are more than those of male, which means that female are more likely to have excitotoxicity and cell death after estrogen therapy. This effect usually counteracts the anti-inflammatory effect of estrogen [117]. Studies also found that estrogen and progesterone are available for TBI treatment. Among them, estrogen is a better choice if used as a prophylactic treatment for women with a high risk of stroke while progesterone is preferred for the male since fewer side effects would happen compared with estrogen $[118,119]$.

In addition to hormone therapy, other treatments for gender differences of TBI are also under investigation. Related researches have been carried out in animal models. Research using pigs to mimic young and older children TBI found that epinephrine (EPI) can prevent damage to the brain's autoregulation and necrosis of hippocampal neurons in both newborn and female juvenile pigs after TBI [120-122]. Phenylephrine (Phe) also had been found to reduce the damage of the $\mathrm{K}$ channel, which can lead to the impairment of cerebral and brain regulation function in female [123].

Hypothermia is a new type of treatment that has long been indicated but is not widely used in clinical practice due to its reversal study findings in both animal models and human trials in brain injury [124-126]. In recent years, investigators found that gender may affect the efficacy of hypothermia [127-129]. In a study of treating TBI rats with hypothermia, post-traumatic hypothermia significantly reduced more overall contusion volume in males than females and protected cortical neurons in males but no effect in females [8].

\section{Conclusion}

Gender has an impact on many aspects of TBI, including clinical manifestations, cognitive impairments, and outcomes, which can be used to develop sex-specific treatment and improve prognosis. This review explores the causal differences in clinical signs, cognitive impairments, medications, and prognosis between males and females after TBI in different dimensions from the view of genes, hormones, cells, individuals, and society. As it turns out that multiple factors contribute to the gender differences after TBI, not merely the perspective of gender and sex hormones. The reason for differences in mortality between male and female after TBI remains inconclusive, but lots of researches have proven that women outperform men in cognitive from cognitive function impairment. Because of these differences between male and female, precise treatment should be taken based on gender. More researches are needed to figure out the entire mechanism of sex difference in TBI, since most studies only focused on the effect of sex hormones. Besides, more attention is needed to compensate for the lack of previous studies which only incorporated into male animals, and clinical studies should not neglect gender differences to avoid bias in real experimental results.

\footnotetext{
Abbreviations

AS: Anxiety sensitivity; CPP: Cerebral perfusion pressure; DA: Dopamine; DAT: Dopamine transporter; E2: 17ß-estradiol; EPI: Epinephrine; GCS: Glasgow Coma Scale; GOS: Glasgow Outcome Scale; ICP: Intracranial pressure; IL1及: Interleukin-1 beta; IL-6: Interleukin-6; OVX: Ovariectomized; PCS: Postconcussive symptoms; Phe: Phenylephrine; POA: Preoptic area; TBI: Traumatic brain injury; TGF- $\beta$ : Transforming growth factor-beta; TNF-a: Tumor necrosis factor-alpha; VMAT-2: Vesicular monoamine transporter-2
}

Acknowledgements

We thank all the participants for their support of this research.

Authors' contributions

$C M, X W, X S, Y Y, Z C, X S$, and $Z W$ were major contributors in conceiving and writing the manuscript. $C M, X W, Y Y$, and $Z C$ wrote the paper with input from 
all authors. XS and ZW conceived the study and were in charge of overall direction and planning. All authors read and approved the final manuscript.

\section{Funding}

Not applicable

\section{Availability of data and materials}

All data generated or analyzed during this study are included in this review.

\section{Ethics approval and consent to participate}

Not applicable

\section{Consent for publication}

Not applicable

\section{Competing interests}

The authors declare that they have no competing interests.

\section{Author details}

'Department of Neurosurgery \& Brain and Nerve Research Laboratory, The First Affiliated Hospital of Soochow University, Jiangsu Province, 188 Shizi Street, Suzhou 215006, China. ${ }^{2}$ Shanghai Medical College, Fudan University, Shanghai 200032, China.

\section{Received: 19 June 2019 Accepted: 20 August 2019}

Published online: 04 October 2019

\section{References}

1. Roozenbeek B, Maas Al, Menon DK. Changing patterns in the epidemiology of traumatic brain injury. Nat Rev Neurol. 2013;9(4):231-6.

2. Maas Al, Stocchetti N, Bullock R. Moderate and severe traumatic brain injury in adults. Lancet Neurol. 2008;7(8):728-41.

3. Peterson, A.B., et al., Surveillance report of traumatic brain injury-related emergency department visits, hospitalizations, and deaths, United States, 2014. 2019.

4. Tiret $L$, et al. The epidemiology of head trauma in Aquitaine (France), 1986: a community-based study of hospital admissions and deaths. Int J Epidemiol. 1990;19(1):133-40

5. Egea-Guerrero JJ, et al. S100B protein may detect brain death development after severe traumatic brain injury. J Neurotrauma. 2013;30(20):1762-9.

6. Leitgeb J, et al. Effects of gender on outcomes after traumatic brain injury. J Trauma. 2011;71(6):1620-6.

7. Hirschberg R, Weiss D, Zafonte R. Traumatic brain injury and gender: what is known and what is not; 2008.

8. Wagner AK, et al. Relationships between cerebrospinal fluid markers of excitotoxicity, ischemia, and oxidative damage after severe TBI: the impact of gender, age, and hypothermia. J Neurotrauma. 2004;21(2):125-36.

9. Vagnerova K, Koerner IP, Hurn PD. Gender and the injured brain. Anesth Analg. 2008;107(1):201-14.

10. Bodhankar $\mathrm{S}$, et al. Role for microglia in sex differences after ischemic stroke: importance of M2. Metab Brain Dis. 2015;30(6):1515-29.

11. Shahrokhi N, et al. Effect of sex steroid hormones on brain edema, intracranial pressure, and neurologic outcomes after traumatic brain injury. Can J Physiol Pharmacol. 2010;88(4):414-21.

12. Sekido $R$. The potential role of SRY in epigenetic gene regulation during brain sexual differentiation in mammals. Adv Genet. 2014;86:135-65.

13. Ho B, et al. X chromosome dosage and presence of SRY shape sex-specific differences in DNA methylation at an autosomal region in human cells. Biol Sex Differ. 2018:9(1):10.

14. Dekaban AS. Changes in brain weights during the span of human life: relation of brain weights to body heights and body weights. Ann Neurol. 1978;4(4):345-56

15. Witelson SF, Kigar DL. Sylvian fissure morphology and asymmetry in men and women: bilateral differences in relation to handedness in men. J Comp Neurol. 1992;323(3):326-40

16. Kulynych JJ, et al. Gender differences in the normal lateralization of the supratemporal cortex: MRI surface-rendering morphometry of Heschl's gyrus and the planum temporale. Cereb Cortex. 1994:4(2):107-18.

17. Holloway RL, et al. Sexual dimorphism of the human corpus callosum from three independent samples: relative size of the corpus callosum. Am J Phys Anthropol. 1993;92(4):481-98.
18. Benbow CP. Sex-differences in mathematical reasoning ability in intellectually talented preadolescents - their nature, effects, and possible causes. Behav Brain Sci. 1988;11(2):169-83.

19. Bayir $\mathrm{H}$, et al. Marked gender effect on lipid peroxidation after severe traumatic brain injury in adult patients. J Neurotrauma. 2004;21(1):1-8

20. Farace $\mathrm{E}$, Alves WM. Do women fare worse: a metaanalysis of gender differences in traumatic brain injury outcome. J Neurosurg. 2000;93(4):539-45.

21. Gan B, Lim J, Ng I. Outcome of moderate and severe traumatic brain injury amongst the elderly in Singapore. Ann Acad Med Singapore. 2004;33(1):63-7.

22. Kirkness CJ, et al. Is there a sex difference in the course following traumatic brain injury? Biol Res Nurs. 2004;5(4):299-310.

23. Wagner AK, et al. Intentional traumatic brain injury: epidemiology, risk factors, and associations with injury severity and mortality. J Trauma Acute Care Surg. 2000;49(3):404-10

24. Munivenkatappa A, et al. Traumatic brain injury: does gender influence outcomes? Int J Crit Illn Inj Sci. 2016;6(2):70.

25. Berry $C$, et al. The effect of gender on patients with moderate to severe head injuries. J Trauma Acute Care Surg. 2009;67(5):950-3.

26. Groswasser Z, Cohen $\mathrm{M}$, Keren $\mathrm{O}$. Female TBI patients recover better than males. Brain Inj. 1998;12(9):805-8.

27. Niemeier JP, et al. Gender differences in executive functions following traumatic brain injury. Neuropsychol Rehabil. 2007;17(3):293-313.

28. Saban $\mathrm{KL}$, et al. Sex differences in perceived life satisfaction and functional status one year after severe traumatic brain injury. J Women's Health. 2011;20(2):179-86.

29. Sarkaki AR, et al. Time-and dose-dependent neuroprotective effects of sex steroid hormones on inflammatory cytokines after a traumatic brain injury. J Neurotrauma. 2013;30(1):47-54

30. Schmidt AT, et al. Decision making after pediatric traumatic brain injury: trajectory of recovery and relationship to age and gender. Int J Dev Neurosci. 2012:30(3):225-30.

31. Ley EJ, et al. Gender impacts mortality after traumatic brain injury in teenagers. J Trauma Acute Care Surg. 2013;75(4):682-6.

32. Albrecht JS, et al. Sex differences in mortality following isolated traumatic brain injury among older adults. J Trauma Acute Care Surg. 2016;81(3):486-92.

33. Renner $C$, et al. The influence of gender on the injury severity, course and outcome of traumatic brain injury. Brain Inj. 2012;26(11):1360-71.

34. Slewa-Younan $\mathrm{S}$, et al. Sex differences in injury severity and outcome measures after traumatic brain injury1. Arch Phys Med Rehabil. 2004:85(3):376-9.

35. Acaz-Fonseca $E$, et al. Sex differences in glia reactivity after cortical brain injury. Glia. 2015:63(11):1966-81.

36. Colantonio A, et al. Gender differences in self reported long term outcomes following moderate to severe traumatic brain injury. BMC Neurol. 2010;10(1):102.

37. Coronado VG, et al. Surveillance for traumatic brain injury-related deaths; United States, 1997-2007. MMWR Surveill Summ. 2011;60(5):1-32.

38. Scott $C$, et al. A comparison of adult outcomes for males compared to females following pediatric traumatic brain injury. Neuropsychology. 2015;29(4):501.

39. Centers for Disease Control and Prevention. Report to congress on traumatic brain injury in the United States: epidemiology and rehabilitation. National Center for Injury Prevention and Control: 2015. pp. 1-72.

40. Mollayeva T, Mollayeva S, Colantonio. Traumatic brain injury: sex, gender and intersecting vulnerabilities. Nat Rev Neurol. 2018;14(12):711-22.

41. De Nicola AF. Steroid hormones and neuronal regeneration. Adv Neurol. 1993:59:199-206.

42. He J, et al. Progesterone and allopregnanolone reduce inflammatory cytokines after traumatic brain injury. Exp Neurol. 2004;189(2):404-12.

43. Djebaili M, Hoffman SW, Stein DG. Allopregnanolone and progesterone decrease cell death and cognitive deficits after a contusion of the rat prefrontal cortex. Neuroscience. 2004;123(2):349-59.

44. Shear DA, et al. Progesterone protects against necrotic damage and behaviora abnormalities caused by traumatic brain injury. Exp Neurol. 2002;178(1):59-67.

45. Hall ED, Gibson TR, Pavel KM. Lack of a gender difference in post-traumatic neurodegeneration in the mouse controlled cortical impact injury model. J Neurotrauma. 2005;22(6):669-79.

46. Pooley $A E_{\text {, et }}$ al. Sex differences in the traumatic stress response: the role of adult gonadal hormones. Biol Sex Differ. 2018;9(1):32

47. Roof RL, Hall ED. Estrogen-related gender difference in survival rate and cortical blood flow after impact-acceleration head injury in rats. J Neurotrauma. 2000:17(12):1155-69.

48. Carswell HV, Dominiczak AF, Macrae IM. Estrogen status affects sensitivity to focal cerebral ischemia in stroke-prone spontaneously hypertensive rats. Am J Physiol Heart Circ Physiol. 2000;278(1):H290-4. 
49. Sarkaki AR, et al. Time- and dose-dependent neuroprotective effects of sex steroid hormones on inflammatory cytokines after a traumatic brain injury. J Neurotrauma. 2013;30(1):47-54.

50. Morrison B III, et al. In vitro central nervous system models of mechanically induced trauma: a review. J Neurotrauma. 1998;15(11):911-28.

51. Olsson T. Critical influences of the cytokine orchestration on the outcome of myelin antigen-specific T-cell autoimmunity in experimental autoimmune encephalomyelitis and multiple sclerosis. Immunol Rev. 1995;144(1):245-68.

52. Ross SA, et al. The presence of tumour necrosis factor in CSF and plasma after severe head injury. Br J Neurosurg. 1994:8(4):419-25.

53. Lawrence CB, Allan SM, Rothwell NJ. Interleukin-1 $\beta$ and the interleukin-1 receptor antagonist act in the striatum to modify excitotoxic brain damage in the rat. Eur J Neurosci. 1998:10(3):1188-95.

54. Lenzlinger PM, et al. The duality of the inflammatory response to traumatic brain injury. Mol Neurobiol. 2001;24(1-3):169-81.

55. Chiaretti A, et al. Nerve growth factor expression correlates with severity and outcome of traumatic brain injury in children. Eur J Paediatr Neurol. 2008;12(3):195-204.

56. Kontos HA, et al. Cerebral arteriolar damage by arachidonic acid and prostaglandin G2. Science. 1980;209(4462):1242-5.

57. Roof RL, Hoffman SW, Stein DG. Progesterone protects against lipid peroxidation following traumatic brain injury in rats. Mol Chem Neuropathol. 1997;31(1):1-11.

58. Morrow JD, et al. Non-cyclooxygenase-derived prostanoids (F2-isoprostanes) are formed in situ on phospholipids. Proc Natl Acad Sci U S A. 1992;89(22):10721-5.

59. Hall ED, Pazara KE, Linseman KL. Sex differences in postischemic neuronal necrosis in gerbils. J Cereb Blood Flow Metab. 1991;11(2):292-8.

60. Bizzozero OA, et al. Elevated protein carbonylation in the brain white matter and gray matter of patients with multiple sclerosis. J Neurosci Res. 2005;81(5):687-95.

61. Sultana R, Butterfield DA. Role of oxidative stress in the progression of Alzheimer's disease. J Alzheimers Dis. 2010;19(1):341-53.

62. Irwin RW, et al. Progesterone and estrogen regulate oxidative metabolism in brain mitochondria. Endocrinology. 2008;149(6):3167-75.

63. Caplan HW, Cox CS, Bedi SS. Do microglia play a role in sex differences in TBI? J Neurosci Res. 2017;95(1-2):509-17.

64. Harry GJ, Kraft AD. Neuroinflammation and microglia: considerations and approaches for neurotoxicity assessment. Expert Opin Drug Metab Toxicol. 2008;4(10):1265-77.

65. Ransohoff RM, Perry VH. Microglial physiology: unique stimuli, specialized responses. Annu Rev Immunol. 2009;27:119-45.

66. Kingham P, Cuzner M, Pocock J. Apoptotic pathways mobilized in microglia and neurones as a consequence of chromogranin A-induced microglial activation. J Neurochem. 1999;73(2):538-47.

67. Polazzi E, Contestabile A. Reciprocal interactions between microglia and neurons: from survival to neuropathology. Rev Neurosci. 2002;13(3):221-42.

68. Ginhoux F, et al. Fate mapping analysis reveals that adult microglia derive from primitive macrophages. Science. 2010;330(6005):841-5.

69. Lenz KM, McCarthy MM. A starring role for microglia in brain sex differences. Neuroscientist. 2015;21(3):306-21.

70. Schafer DP, et al. Microglia sculpt postnatal neural circuits in an activity and complement-dependent manner. Neuron. 2012;74(4):691-705.

71. Schwarz JM, Sholar PW, Bilbo SD. Sex differences in microglial colonization of the developing rat brain. J Neurochem. 2012:120(6):948-63.

72. McCarthy MM, Wright CL, Schwarz JM. New tricks by an old dogma: mechanisms of the organizational/activational hypothesis of steroidmediated sexual differentiation of brain and behavior. Horm Behav. 2009; 55(5):655-65.

73. Lenz KM, et al. Microglia are essential to masculinization of brain and behavior. J Neurosci. 2013;33(7):2761-72

74. Davis EC, Popper P, Gorski RA. The role of apoptosis in sexual differentiation of the rat sexually dimorphic nucleus of the preoptic area. Brain Res. 1996;734(1-2):10-8.

75. Villapol S, Loane DJ, Burns MP. Sexual dimorphism in the inflammatory response to traumatic brain injury. Glia. 2017;65(9):1423-38.

76. Crain JM, Nikodemova M, Watters JJ. Microglia express distinct M1 and M2 phenotypic markers in the postnatal and adult central nervous system in male and female mice. J Neurosci Res. 2013:91(9):1143-51.

77. Chen Y, et al. Targeting microglial activation in stroke therapy: pharmacological tools and gender effects. Curr Med Chem. 2014;21(19):2146-55.

78. Barreto $\mathrm{G}$, et al. Testosterone decreases reactive astroglia and reactive microglia after brain injury in male rats: role of its metabolites, oestradio and dihydrotestosterone. Eur J Neurosci. 2007;25(10):3039-46.
79. Habib P, Beyer C. Regulation of brain microglia by female gonadal steroids. J Steroid Biochem Mol Biol. 2015;146:3-14.

80. Crosson B, Haaland KY. Subcortical functions in cognition: toward a consensus. J Int Neuropsychol Soc. 2003;9(7):1027-30.

81. Donnemiller $\mathrm{E}$, et al. Impaired dopaminergic neurotransmission in patients with traumatic brain injury: a SPECT study using 1231-beta-CIT and 1231IBZM. Eur J Nucl Med. 2000;27:1410-4

82. Wagner AK, et al. Gender and environmental enrichment impact dopamine transporter expression after experimental traumatic brain injury. Exp Neurol. 2005;195(2):475-83.

83. Brown JM, et al. Differential protection against MPTP or methamphetamine toxicity in dopamine neurons by deletion of ppN/OFQ expression. $J$ Neurochem. 2006:98(2):495-505.

84. Xu X, et al. Sex-related differences in striatal dopaminergic system after traumatic brain injury. Brain Res Bull. 2016;124:214-21.

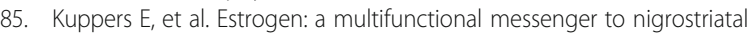
dopaminergic neurons. J Neurocytol. 2000;29(5-6):375-85.

86. Castner SA, Xiao L, Becker JB. Sex differences in striatal dopamine: in vivo microdialysis and behavioral studies. Brain Res. 1993;610(1):127-34.

87. Morissette $M$, et al. Sex and estrous cycle variations of rat striatal dopamine uptake sites. Neuroendocrinology. 1993;58:16-22.

88. Rivest $\mathrm{R}$, et al. Brain dopamine transporter: gender differences and effect of chronic haloperidol. Brain Res. 1995;692:269-72.

89. Lavalaye J, et al. Effect of age and gender on dopamine transporter imaging with [123I] FP-CIT SPET in healthy volunteers. Eur J Nucl Med. 2000;27:867-9.

90. Caplan B, et al. A dopamine pathway gene risk score for cognitive recovery following traumatic brain injury: methodological considerations, preliminary findings, and interactions with sex. J Head Trauma Rehabil. 2016;31(5):E15-29.

91. Basso MR, et al. FORUM sex differences on the WMS-III: findings concerning verbal paired associates and faces. Clin Neuropsychol. 2000;14(2):231-5.

92. Halari $\mathrm{R}$, et al. Sex differences and individual differences in cognitive performance and their relationship to endogenous gonadal hormones and gonadotropins. Behav Neurosci. 2005;119(1):104.

93. Janowsky JS, et al. The cognitive neuropsychology of sex hormones in men and women. Dev Neuropsychol. 1998;14(2-3):421-40.

94. Ryan LM, Warden DL. Post concussion syndrome. Int Rev Psychiatry. 2003: 15(4):310-6

95. Schmidt NB, Koselka M. Gender differences in patients with panic disorder: evaluating cognitive mediation of phobic avoidance. Cogn Ther Res. 2000; 24(5):533-50.

96. Albanese BJ, et al. Anxiety sensitivity mediates gender differences in postconcussive symptoms in a clinical sample. Psychiatry Res. 2017;252:242-6.

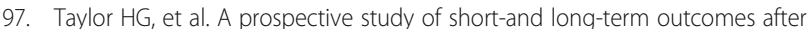
traumatic brain injury in children: behavior and achievement. Neuropsychology. 2002;16(1):15.

98. Donders J, Hoffman NM. Gender differences in learning and memory after pediatric traumatic brain injury. Neuropsychology. 2002;16(4):491-9.

99. Donders J, Woodward HR. Gender as a moderator of memory after traumatic brain injury in children. J Head Trauma Rehabil. 2003:18(2):106-15.

100. Duff MC, et al. Beyond utterances: distributed cognition as a framework for studying discourse in adults with acquired brain injury. Semin Speech Lang. 2012;33:44-54 NIH Public Access.

101. Späni CB, Braun DJ, Van Eldik $\sqcup$. Sex-related responses after traumatic brain injury: considerations for preclinical modeling. Front Neuroendocrinol. 2018;50:52-66.

102. Anderson $\mathrm{V}$, et al. Social competence at 6 months following childhood traumatic brain injury. J Int Neuropsychol Soc. 2013;19(5):539-50.

103. Jones CA, Turkstra LS. Selling the story: narratives and charisma in adults with TBI. Brain Inj. 2011;25(9):844-57.

104. Yeates $\mathrm{KO}$, et al. Peer relationships of children with traumatic brain injury. J Int Neuropsychol Soc. 2013;19(5):518-27.

105. Hartley LL, Levin HS. Linguistic deficits after closed head-injury - a current appraisal. Aphasiology. 1990;4(4):353-70.

106. Despins EH, et al. Sex-based differences in perceived pragmatic communication ability of adults with traumatic brain injury. Arch Phys Med Rehabil. 2016;97(2 Suppl):S26-32.

107. Babbage DR, et al. Meta-analysis of facial affect recognition difficulties after traumatic brain injury. Neuropsychology. 2011;25(3):277-85.

108. Rosenberg $\mathrm{H}$, et al. Emotion perception after moderate-severe traumatic brain injury: the valence effect and the role of working memory, processing speed, and nonverbal reasoning. Neuropsychology. 2015:29(4):509. 
109. Green RE, Turner GR, Thompson WF. Deficits in facial emotion perception in adults with recent traumatic brain injury. Neuropsychologia. 2004;42(2):133-41.

110. Weisenbach $S L$, et al. Reduced emotion processing efficiency in healthy males relative to females. Soc Cogn Affect Neurosci. 2014;9(3):316-25.

111. Rigon A, et al. The female advantage: sex as a possible protective factor against emotion recognition impairment following traumatic brain injury. Cogn Affect Behav Neurosci. 2016;16(5):866-75.

112. Mychasiuk R, et al. Mean girls: sex differences in the effects of mild traumatic brain injury on the social dynamics of juvenile rat play behaviour. Behav Brain Res. 2014;259:284-91.

113. Behl C, Holsboer F. The female sex hormone oestrogen as a neuroprotectant. Trends Pharmacol Sci. 1999;20(11):441-4.

114. Frankfurt M. Gonadal steroids and neuronal plasticity. Studies in the adult rat hypothalamus. Ann N Y Acad Sci. 1994;743:45-59 discussion 59-60.

115. Matsumoto A, Arai Y. Male-female difference in synaptic organization of the ventromedial nucleus of the hypothalamus in the rat. Neuroendocrinology. 1986;42(3):232-6.

116. Smith SS. Estrogen administration increases neuronal responses to excitatory amino-acids as a long-term effect. Brain Res. 1989;503(2):354-7.

117. Brown TJ, et al. Regional sex differences in cell nuclear estrogen-binding capacity in the rat hypothalamus and preoptic area. Endocrinology. 1988; 123(4):1761-70.

118. Stein DG. Brain damage, sex hormones and recovery: a new role for progesterone and estrogen? Trends Neurosci. 2001;24(7):386-91.

119. Brotfain $\mathrm{E}$, et al. Neuroprotection by estrogen and progesterone in traumatic brain injury and spinal cord injury. Curr Neuropharmacol. 2016; 14(6):641-53.

120. Armstead WM, Vavilala MS. Adrenomedullin reduces gender-dependent loss of hypotensive cerebrovasodilation after newborn brain injury through activation of ATP-dependent K channels. J Cereb Blood Flow Metab. 2007; 27(10):1702-9

121. Armstead WM, et al. Combination therapy with glucagon and a novel plasminogen activator inhibitor-1-derived peptide enhances protection against impaired cerebrovasodilation during hypotension after traumatic brain injury through inhibition of ERK and JNK MAPK. Neurol Res. 2012;34(6):530-7.

122. Armstead WM, Riley J, Vavilala MS. K channel impairment determines sex and age differences in epinephrine-mediated outcomes after brain injury. J Neurosci Res. 2017;95(10):1917-26.

123. Armstead WM, Riley J, Vavilala MS. TBI sex dependently upregulates ET-1 to impair autoregulation, which is aggravated by phenylephrine in males but is abrogated in females. J Neurotrauma. 2012;29(7):1483-90.

124. Yamamoto M, et al. Neuroprotective effect of hypothermia on neuronal injury in diffuse traumatic brain injury coupled with hypoxia and hypotension. J Neurotrauma. 1999;16(6):487-500.

125. Shiozaki T, Mild Hypothermia Study Group in Japan, et al. A multicenter prospective randomized controlled trial of the efficacy of mild hypothermia for severely head injured patients with low intracranial pressure. J Neurosurg. 2001;94(1):50-4.

126. Clifton GL, et al. Lack of effect of induction of hypothermia after acute brain injury. N Engl J Med. 2001:344(8):556-63.

127. Suzuki T, Bramlett HM, Dietrich WD. The importance of gender on the beneficial effects of posttraumatic hypothermia. Exp Neurol. 2003;184(2):1017-26.

128. Lyeth $B G$, et al. Hypothermia blunts acetylcholine increase in CSF of traumatically brain injured rats. Mol Chem Neuropathol. 1993;18(3):247-56.

129. Davies A. Hypothermia improves outcome from traumatic brain injury. Crit Care Resusc. 2005;7(3):238.

\section{Ready to submit your research? Choose BMC and benefit from:}

- fast, convenient online submission

- thorough peer review by experienced researchers in your field

- rapid publication on acceptance

- support for research data, including large and complex data types

- gold Open Access which fosters wider collaboration and increased citations

- maximum visibility for your research: over $100 \mathrm{M}$ website views per year

At BMC, research is always in progress.

Learn more biomedcentral.com/submissions 